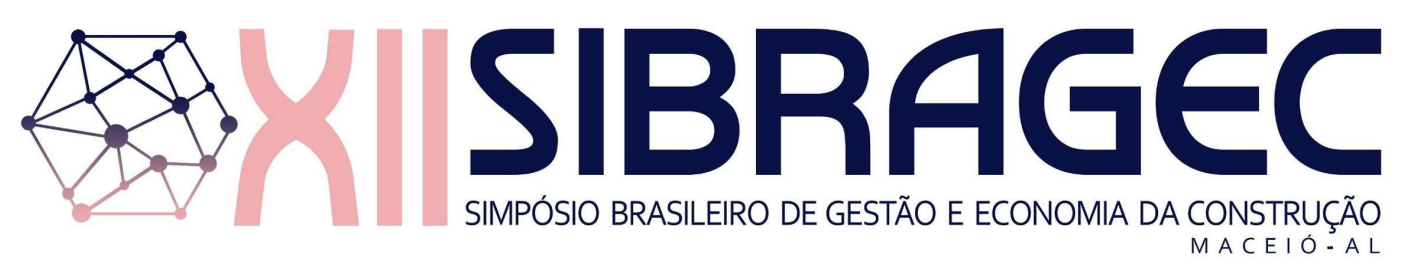

\title{
AÇÕES DE ENFRENTAMENTO À PANDEMIA DE COVID-19 EM DUAS CONSTRUTORAS DO INTERIOR PAULISTA ${ }^{1}$
}

\author{
ROCHA, Leonardo Brian Gonçalves da (1); SARTI JUNIOR, Luiz Antonio (2); \\ SERRA, Sheyla Mara Baptista (3)
}

(1) Universidade Federal de São Carlos, 1l.brian@hotmail.com (2) Universidade Federal de São Carlos, luiz.sarti.junior@gmail.com (3) Universidade Federal de São Carlos, sheylabs@ufscar.br

\begin{abstract}
RESUMO
As atividades da construção civil foram consideradas como serviço essencial e continuou suas atividades seguindo os protocolos recomendados pelos órgãos de saúde. Diversas medidas preventivas foram implantadas no setor para evitar a propagação do vírus de COVID-19. Esse estudo objetivou conhecer por meio de estudo de caso o desenvolvimento de ações alternativas que podem ser adotadas por empresas construtoras a fim de evitar contaminações no canteiro de obras durante este período, e também verificar as ações tomadas caso haja a contaminação. Foram analisadas legislações vigentes acerca do combate ao COVID-19, e aplicado questionários aos trabalhadores de duas empresas construtoras analisando os protocolos de saúde, higiene, proteção individual e segurança no canteiro. Conclui-se que é importante estabelecer uma gestão integrada aos protocolos de enfrentamento da COVID-19.
\end{abstract}

Palavras-chave: COVID-19, Segurança do trabalho, Canteiro de obras, Construção civil.

\begin{abstract}
Civil construction activities were considered an essential service and it continued its activities following the protocols recommended by the health agencies. Several preventive measures have been implemented in the sector to prevent the spread of the COVID-19 virus. This study aimed to learn, through a case study, the development of alternative actions that can be adopted by construction companies in order to avoid contamination on the construction site during this period, and also to verify the actions taken in case of contamination. Current legislation on combating COVID-19 was analyzed, and questionnaires were applied to workers from two construction companies analyzing the health, hygiene, personal protection and safety protocols at the jobsite. We conclude that it is important to establish a management integrated with the COVID-19 coping protocols.
\end{abstract}

Keywords: COVID-19, Safety in the workplace, Construction site, Construction industry.

\section{INTRODUÇÃO}

Para garantir o bom desenvolvimento econômico de um país, diversos setores industriais e produtivos impulsionam a economia local das grandes e pequenas cidades fazendo a geração de empregos para a população. Segundo o Sinduscon-SP (2020) a construção

ROCHA, L. B. G; SARTI JUNIOR, L. A.; SERRA, S. M. B. AçÕes de enfrentamento à pandemia de covid-19 em duas construtoras do interior paulista. In: SIMPÓSIO BRASILEIRO DE GESTÃO E ECONOMIA DA CONSTRUÇÃO, 12., 2021, Maceió, Alagoas. Anais[...] Porto Alegre: ANTAC, 2021. p.1-8. Disponível em: https://eventos.antac.org.br/index.php/sibragec/article/view/493. Acesso em: 2 out. 2021. 
civil representa 6,2\% do Produto Interno Bruto (PIB) brasileiro e é responsável por movimentar cerca de 70 setores da economia nacional.

A Norma Regulamentadora NR 4 (2016), classifica a construção civil sendo o setor com o maior risco de acidentes do trabalho e um fator muito importante que vem sendo discutido nos últimos anos e que possui um grande impacto no crescimento de empresas construtoras é a saúde e segurança dos trabalhadores em canteiros de obras.

Alguns fatores afetam diretamente o desempenho da saúde e segurança, analisando os principais aspectos, observa-se que as taxas de acidentes e contaminação em canteiros estão relacionadas as atitudes do trabalhador, políticas de segurança da empresa, treinamento gerencial e cultural, coordenação de projetos e pressão econômica (Lee et al., 2020). Para atender a demanda de produtividade, alguns procedimentos de segurança acabam não sendo seguidos para concluir os trabalhos em um curto período.

As medidas de segurança de combate ao COVID-19 trouxeram um novo comportamento social, espaços com grandes aglomerações de pessoas não podem ter o mesmo ritmo de funcionamento, afetando diretamente a uma vasta cadeia produtiva e toda sua mão de obra. De acordo com Joshi, Bhaskar e Gupta (2020) em um cenário totalmente incerto provocado pela pandemia da COVID-19 as empresas vem sofrendo impactos significativos de mudanças internas e externas. Medidas de distanciamento social fazem com que as rotinas de trabalho e logística dos escritórios e canteiros de obras sejam feitas com um número reduzido de funcionários, influenciando diretamente no prazo de término final da obra. As principais recomendações dos órgãos de saúde não foram medidas direcionadas especificamente para a indústria da construção civil. De acordo com a Câmara Brasileira da Indústria da Construção (CBIC), inicialmente foram indicados o afastamento imediato de pessoas classificadas como integrantes do grupo de risco, como idosos, portadores de doenças especiais, doenças autoimunes, e pessoas com sintomas gripais suspeitos (CBIC, 2020). Aos poucos, os órgãos governamentais de saúde foram implantando em cada setor específico medidas de restrições, tornando obrigatória em todo o território nacional.

A elaboração de um plano de gestão eficiente, que busca criar metodologias eficazes e preventivas com a participação direta dos funcionários, com o objetivo de garantir a produtividade sem comprometer a segurança, saúde e qualidade de vida dos colaboradores ainda que o maior desafio seja o controle de tais práticas, com os cuidados e prevenções diárias adotados como regra da construtora e com acompanhamento contínuo é possível garantir a proteção da saúde de todos os setores envolvidos.

Com a expectativa de contribuir no desenvolvimento do setor e garantir a manutenção dos empregos, preservando a saúde física, mental e a segurança do trabalhador, surge a necessidade de que as empresas construtoras utilizem estratégias voltadas para garantir o bom funcionamento de suas atividades.

O objetivo desse artigo é realizar um levantamento de informações e relatar a atuação de construtoras neste cenário de pandemia de COVID-19. Com isso, espera-se apresentar estratégias utilizadas para garantir o controle e prevenção da problemática evidenciada, com foco na saúde, segurança e qualidade de vida dos trabalhadores da construção civil.

\section{FUNDAMENTAÇÃO TEÓRICA}

\subsection{Crescimento de obras durante a pandemia da COVID-19}


Segundo Halpin (2015), por atender uma demanda de diversas atividades, o setor da construção civil pode ser considerado como serviço essencial, sendo responsável por serviços que garantem a qualidade de vida da população. Entre os principais serviços abrangidos pelo setor podem ser citados o abastecimento de água e destinação de esgoto, estações de tratamento, execução e manutenção de rodovias, construção de residências, edifícios multifuncionais, pontes, usinas de energia elétrica entre outros empreendimentos que garantem um bom funcionamento de um país. O Decreto $\mathrm{N}^{\mathrm{o}} 10.342$ (BRASIL, 2020), considerando as atividades de construção civil como serviço essencial foi assinado pelo Presidente da República e publicado em 7 de maio de 2020.

Segundo Ribeiro (2020), a paralisação do comércio e de serviços considerados não essenciais forçaram as famílias a passarem mais tempo dentro de suas residências. A adaptação do lar como ambiente de trabalho e o maior tempo de permanência no mesmo estimulou a realização de obras residenciais e comerciais.

De acordo com Sinduscon-SP (2021), o número de casos confirmados de COVID-19 nas empresas construtoras do estado de São Paulo caiu de 0,50\% para 0,23\%. Os casos considerados suspeitos permaneceram estáveis com $0,55 \%$. Os dados foram obtidos através da pesquisa "Conhecendo as ações das construtoras paulistas no combate à COVID-19". A pesquisa contou com a colaboração de 50 empresas que estão com 567 obras em andamento, total de 37.340 funcionários diretos e terceirizados. Das 567 obras em andamento, apenas uma está parada, garantindo $98 \%$ dos trabalhadores em atividade.

\subsection{Realização de treinamentos}

Com investimento em treinamentos e qualificação dos operários e gestores, a empresa contribui diretamente para a conscientização e prevenção de acidentes. Os funcionários devem ser incentivados a se envolverem nas decisões que os afetam diretamente, visando a aumentar o comprometimento e a percepção de que há certo controle em relação àquilo que os impacta. De acordo com Dekker e Woods (2010), a realização de treinamentos garante qualidade nos serviços executados e melhoram o desempenho em relação a saúde e segurança do trabalhador.

Segundo CBIC (2020), as orientações referentes aos treinamentos para os trabalhadores da construção civil são: uso adequado de álcool em gel, considerando seu risco de combustão; uso correto das máscaras faciais; limpeza correta das ferramentas e equipamentos; distanciamento social mínimo de dois metros; entrega de materiais informativos de métodos de prevenção ao vírus.

\subsection{Prevenção de contaminação nos canteiros de obras}

Em diversos países, as organizações de fiscalização da segurança laboral estão propondo diretrizes especificas para enfrentamento da pandemia por setor industrial. É o caso da Occupational Safety and Health Administration (OSHA, 2021), que também publicou orientações direcionadas à indústria da construção. Foram classificados alguns níveis de risco de exposição da COVID-19 que são determinados por baixo até muito alto.

De acordo com OSHA (2021), as tarefas de baixo risco são as que os trabalhadores conseguem garantir um distanciamento mínimo de dois metros e ter pouco contato com clientes e fornecedores. As tarefas consideradas de alto risco incluem trabalhar em um ambiente de trabalhado interno como hospital, ocupado por muitos trabalhadores, clientes ou residentes que apresentam qualquer sintoma ou estão infectados pela COVID-19. Por 
meio dessa classificação de níveis de risco, devem ser adotadas as medidas de prevenção de contaminação da doença.

Outra solução implantada nos canteiros de obra para garantir o distanciamento mínimo adequado, é o uso adicional de tecnologias. Aparelhos de comunicação como rádios integrados estão sendo adquiridos pelas construtoras para facilitar a comunicação entre os trabalhadores (OSHA, 2021).

Para CBIC (2020), as principais medidas para evitar a propagação da doença nos canteiros de obras são:

- A empresa deve fornecer lavatórios com água e sabão, álcool 70\% e orientar os trabalhadores do seu uso no início dos trabalhos e a cada duas horas. Ambientes fechados devem ser mantidos ventilados, retirando qualquer barreira que impeça a circulação do ar.

- Ferramentas, equipamentos e máquinas de uso manual devem ser constantemente higienizados antes e durante a execução da atividade.

- Controlar a entrada e circulação de pessoas que não trabalham no canteiro, se for necessário a entrada de fornecedores de materiais, restringir a um ambiente próprio de carga e descarga em um tempo máximo determinado.

- Manter o distanciamento social em ambientes fechados do canteiro de obras, como escritórios e refeitórios preservando a separação mínima de dois metros.

- Avaliar a possibilidade de turnos em horários diferentes para evitar aglomerações no transporte coletivo.

- Se apresentar qualquer sintoma relacionado ao COVID-19, o funcionário deverá ser afastado imediatamente de suas atividades e direcionado aos serviços médicos.

- Propor trabalho em home office aos funcionários que não trabalham no setor de produção.

- Afastamento imediato de pessoas consideradas do grupo de risco que apresentam condições de saúde pré-existentes, como diabetes, hipertensão ou problemas respiratórios.

- Aplicação diária de questionário conferindo as condições de saúde do trabalhador e de seus familiares antes de iniciar o expediente para identificação rápida dos casos que podem levar as condições de isolamento recomendadas pela OMS.

\section{MÉTODO DE PESQUISA}

De acordo com Yin (2010), o estudo de caso é indicado para o pesquisador que busca resolver questões que explicam as circunstâncias atuais de um problema social, esclarecendo como e porque ele funciona. De maneira geral, o estudo problematiza uma situação a fim de aproximar a teoria e a prática.

O presente artigo apresenta dois estudos de caso em canteiro de obras de diferentes empresas que aceitaram participar da pesquisa. A empresa (A) executa ampliações, reformas e manutenção em prédios do setor público e a empresa (B) executa obras comerciais do setor privado. Ambas atuam em cidades do interior de São Paulo, como Ribeirão Preto (Obra A) e São Carlos (Obra B). O estudo foi conduzido no período de janeiro a abril de 2021. A Obra A se caracteriza como execução de reforma de uma escola municipal e no período da pesquisa contava com cerca de 18 trabalhadores no canteiro. A Obra B se caracteriza como reforma e ampliação de estabelecimento hospitalar e no período da pesquisa contava com cerca de 30 trabalhadores no canteiro. A Obra A se encontra distante do centro urbano disponibilizando transporte coletivo para os 
trabalhadores no início e ao final do período diário de trabalho. A Obra B se localiza em centro urbano, não disponibilizando transporte exclusivo.

O método de pesquisa foi referenciado através de pesquisas bibliográficas exploratórias, comparando o cenário atual da pandemia, a fim de analisar as medidas que as empresas construtoras estão adotando em seus canteiros de obras e propor ações de melhorias para combater os impactos causados pela pandemia de COVID-19 nos trabalhadores.

Foram realizadas visitas nos canteiros de obras e reuniões com os gestores, com registros fotográficos das tarefas sendo realizadas, observando os protocolos exigidos. Também foram aplicados questionários junto aos trabalhadores, buscando identificar se as medidas definidas estavam sendo aplicadas na empresa, e se essas medidas estavam colaborando positivamente para evitar a propagação do vírus dentro do canteiro. Posteriormente, foram recolhidos os questionários e iniciou-se o processo de comparação de resultados.

\section{RESULTADOS E DISCUSSÕES}

Para não precisar pausar suas atividades devido a pandemia de COVID-19, as empresas das Obras A e B iniciaram um levantamento de dados disponibilizados pela Organização Mundial da Saúde (OMS) e pelos sindicatos da região, e com base nessas informações, identificaram e elaboraram uma análise, especificando os objetivos a serem alcançados. Com os principais problemas identificados, criou-se um plano de ação com treinamentos informativos e entrega de kits de proteção aos funcionários. Com isso, esperava-se que os trabalhadores pudessem executar os processos construtivos com segurança.

Após iniciar o plano de ação, foram monitoradas a realização das atividades nos canteiros para identificar possíveis melhorias nos métodos aplicados. Havendo resultados negativos no plano de ação, imediatamente eram aplicadas medidas corretivas nesse processo eliminando as possibilidades de recorrência do problema e reiniciando novas diretrizes.

Os trabalhadores das empresas responderam questionários relacionados a saúde e segurança nos canteiros de obras. O Gráfico 1 apresenta os resultados dos protocolos de apoio a saúde relativos à opinião dos funcionários da empresa $\mathrm{A}$ e $\mathrm{B}$, quanto as possíveis estratégias para a prevenção da COVID-19. Na empresa A, 62\% dos entrevistados responderam que respondem um questionário de avaliação de saúde semanalmente com muita frequência. Na empresa B, esse percentual foi de $63 \%$, o que mostra que ambas as empresas procuram saber sobre o estado de saúde de seus colaboradores.

Quanto ao monitoramento da temperatura corporal e de possíveis sintomas gripais, $89 \%$ dos trabalhadores da empresa A responderam que esse procedimento é realizado diariamente antes de iniciarem suas atividades, enquanto na empresa $\mathrm{B}$ a porcentagem foi de $83 \%$, conforme Gráfico 2 .

Gráfico 1 - Questionário sobre avaliação da saúde

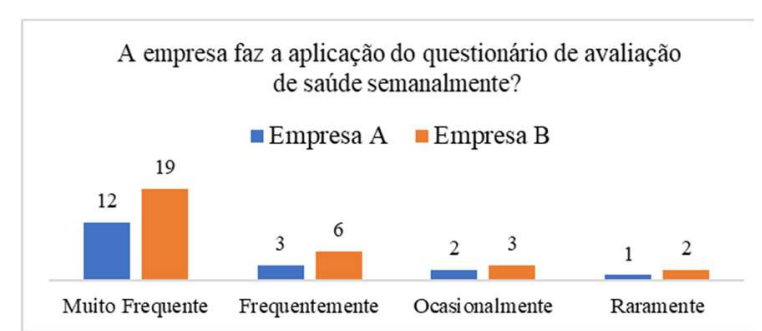

Fonte: os autores.
Gráfico 2-Questionário sobre monitoramento de sintomas

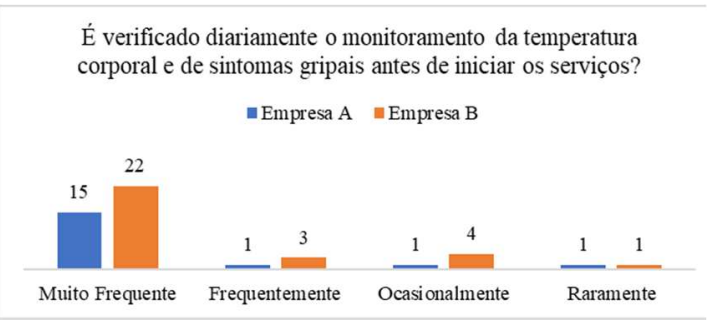


Os trabalhadores também responderam um questionário a respeito do fornecimento de proteção facial no local de trabalho. Segundo o Gráfico 3, 94\% dos trabalhadores da empresa A responderam que a empresa fornece máscaras de proteção facial com muita frequência para serem usadas no local de trabalho, enquanto na empresa B, 87\% disseram receber o EPI muito frequentemente. Quando perguntado se a empresa comunica constante sobre as determinações dos decretos relacionados a COVID-19, 72\% dos trabalhadores da empresa A responderam que são comunicados muito frequentemente e frequentemente enquanto na empresa B o percentual foi de 67\% (Gráfico 4).

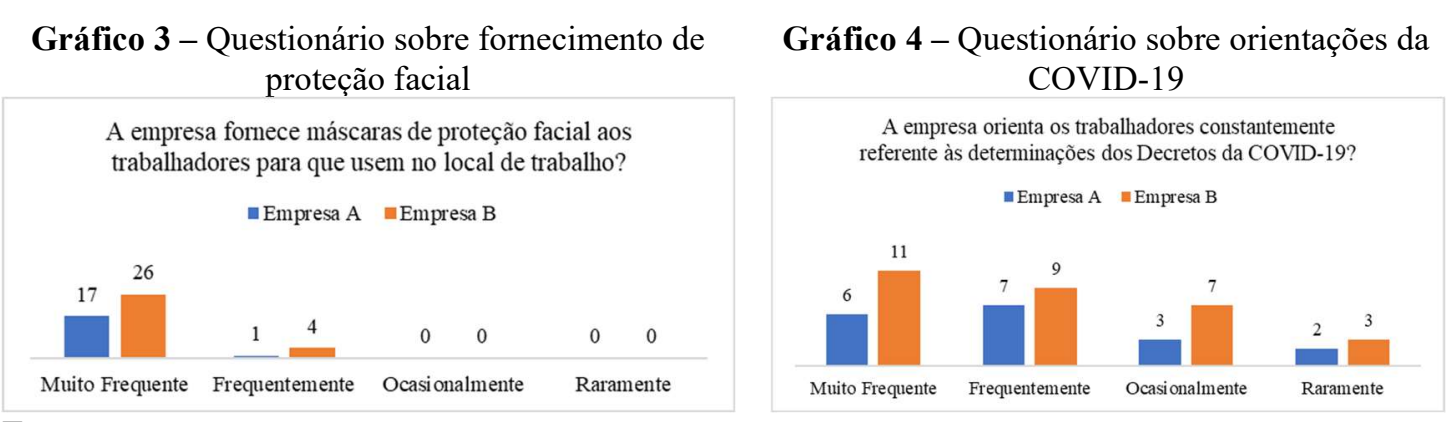

Fonte: os autores.

Ainda segundo os questionários, $91 \%$ dos trabalhadores da empresa A e $92 \%$ da empresa $\mathrm{B}$ disseram que é disponibilizado álcool em gel 70\% durante toda jornada de trabalho. As empresas têm realizado controle de circulação de pessoas externas na obra, com acesso restrito de fornecedores e clientes. Neste sentido, $85 \%$ dos trabalhadores responderam que essa rotina de controle é muito frequente na empresa $\mathrm{A}$, e $78 \%$ na empresa $\mathrm{B}$. A distribuição de kits de uniformes para trocas diárias de roupas pelos funcionários tem sido uma prática adotada por ambas as empresas.

\subsection{Medidas alternativas para evitar a contaminação em canteiros}

Para garantir maior proteção para os trabalhadores, as construtoras aplicaram medidas extras de segurança para evitar a contaminação. A empresa A passou a exigir que seus funcionários façam a substituição de suas máscaras a cada três horas desde o início de suas atividades. Para controlar essa exigência, a empresa A distribuiu dois kits com quatro máscaras reutilizáveis com cores diferentes (Figura 1). No início das atividades às sete horas os funcionários utilizam a máscara Preta 01 , às dez horas é feito a substituição pela máscara branca 02 , às treze horas a máscara verde 03 e às dezesseis horas a máscara cinza 04, encerrando o expediente as dezessete horas. Durante as refeições as mesas do refeitório são demarcadas com fitas indicando os locais de assento garantindo o distanciamento mínimo obrigatório (Figura 2).

Figura 1 - Montagem dos Kits diários de máscaras protetivas

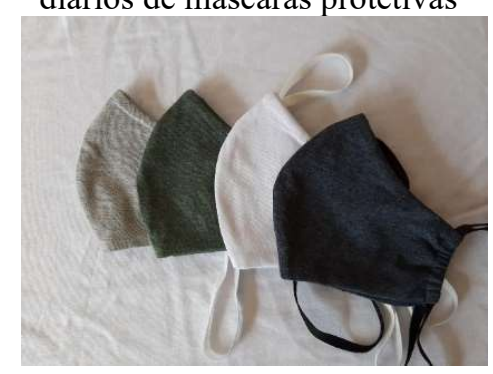

Fonte: Obra A
Figura 2 - Distanciamento social no refeitório A e B

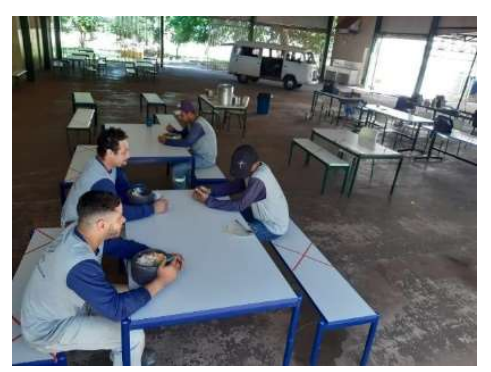

Fonte: Obra A

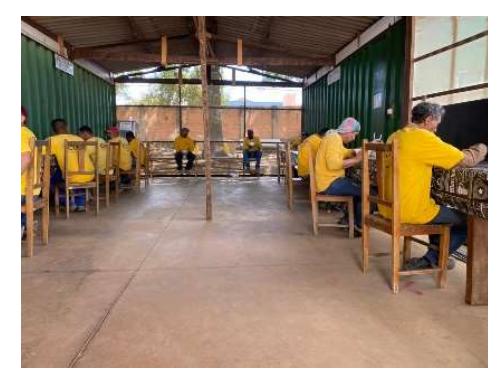

Fonte: Obra B 
Antes de entrarem no transporte coletivo da obra A, é aplicado um questionário informativo de sintomas relacionados a COVID-19 como sinais gripais, febre, falta de paladar ou qualquer sintoma relacionado, individual e familiar (Figura 3). Também é conferido por meio de um termômetro digital infravermelho a temperatura corporal de todos os funcionários pelo técnico de segurança do trabalho das empresas (Figura 4), e se for identificado qualquer alteração, o mesmo é encaminhado imediatamente para o hospital para ser realizado os exames recomendados. Todas as ferramentas e equipamentos são higienizados antes e após o uso (Figura 5).

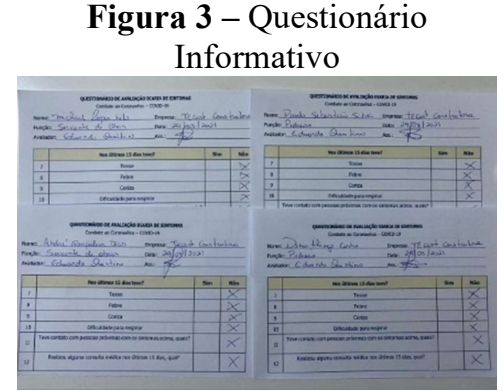

Fonte: Empresa A
Figura 4 - Medição de temperatura

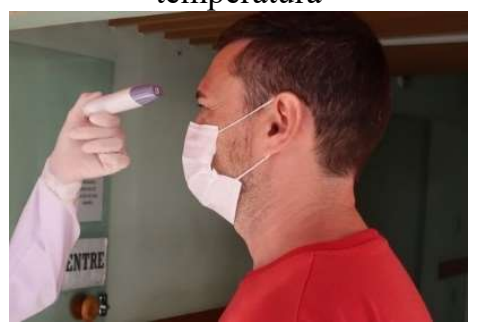

Fonte: Obra A
Figura 5 - Limpeza de maquinas

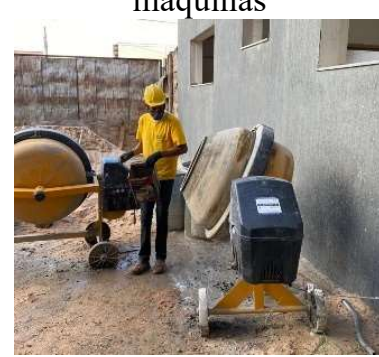

Fonte: Obra B

A empresa A distribui para cada funcionário cinco uniformes que devem ser trocados diariamente e utilizados apenas dentro do canteiro de obras, é vedado o uso desses uniformes no trajeto de ida e volta no transporte coletivo. Os assentos, portas e maçanetas são higienizados com álcool $70 \%$ antes dos funcionários entrarem no veículo, evitando a contaminação direta. São orientados constantemente sobre o distanciamento social no desenvolvimento das atividades diárias, intercalação de assentos nos refeitórios, tarefas realizadas individual (Figura 6), em grupos de no máximo três pessoas, a digital dos pontos foi trocada por cartões (Figura 7) e determinado faixas de distanciamento de 1,5 metros quando forem passar.

Figura 6 - Atividades em grupos com distanciamento

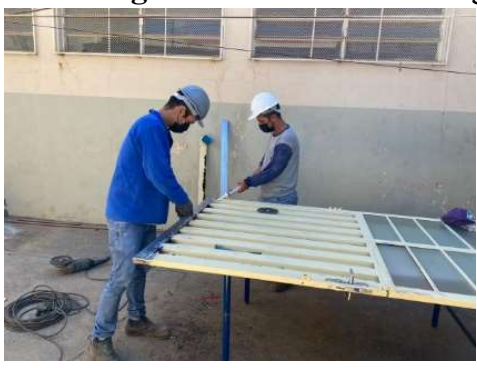

Fonte: Obra A

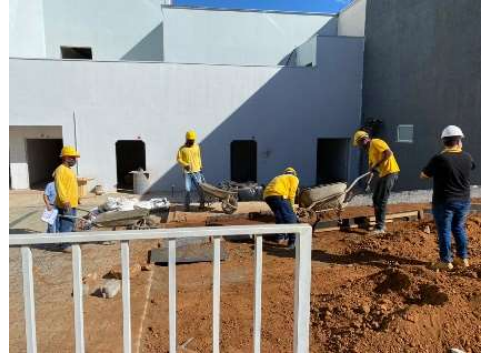

Fonte: Obra B

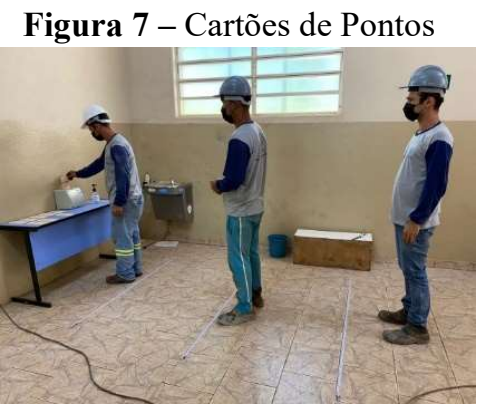

Fonte: Obra A

Em áreas especificas de uso comum, em bebedouros e banheiros, houve a distribuição de cartazes comunicativos de combate ao COVID-19 para incentivar a conscientização dos funcionários. Esse contém informações dos protocolos de segurança como o uso e descarte correto das máscaras, uso do álcool e gel e o correto recebimento de materiais e fornecedores externos dentro do canteiro de obras.

\section{CONCLUSÃO}

Os protocolos de segurança adotados pelas construtoras do estudo de caso para evitar a propagação da COVID-19 como a medição de temperatura, substituição de máscaras de três em três horas, questionário informativo de saúde diária, controle de distanciamento nas atividades em grupos, disponibilização de uniformes para trocas diárias, exigência de embarque no transporte coletivo com roupas limpas, exposição de cartazes informativos 
de conscientização tem se mostrado eficazes para evitar a contaminação dos funcionários contra da COVID-19.

Com essas restrições, as empresas adaptaram uma nova realidade no canteiro de obras, com mudanças fundamentadas de acordo com o novo cenário atual, buscando viabilizar as necessidades exigidas de maneira segura para todos os seus funcionários. Verificou-se que os protocolos adotados por essas empresas necessitaram de investimento financeiro, mas os resultados foram significativos, pois eles contribuíram para aumentar a segurança e saúde dos funcionários presentes no canteiro de obras.

Diante do cenário atual de pandemia, as empresas precisam adotar os protocolos de segurança preconizados pela Organização Mundial da Saúde (OMS), além de adotar medidas adicionais de acordo com as especificidades de cada empresa, visando formas de evitar a propagação do vírus dentro do canteiro de obras.

\section{REFERENCIAS}

BRASIL. Decreto No 10.342. Definir os serviços públicos e as atividades essenciais. 2020. Disponível em: https://www.in.gov.br/web/dou/-/decreto-n-10.342-de-7-de-maio-de-2020-255709739. Acesso em: $27 \mathrm{de}$ jun. de 2021.

BRASIL. Ministério do Trabalho. Norma Regulamentadora NR 4: Serviços Especializados em Engenharia de Segurança e em Medicina do Trabalho, 2016. Disponível em: http://www.mte.gov.br. Acesso em: 27 de jun. de 2021.

BRASIL. Ministério do Trabalho. Norma Regulamentadora NR 6: Equipamentos de Proteção Individual. ABNT, 2010. Disponível em: http://www.mte.gov.br. Acesso em: 25 de jun. de 2021.

CÂMARA BRASILEIRA DA INDÚSTRIA DA CONSTRUÇÃO (CBIC). A pandemia do coronavírus: Recomendações para o ambiente de trabalho na indústria da construção, 2020. Disponível em: https://cbic.org.br/wp-content/uploads/2020/03/A_pandemia_do_coronavirus.pdf. Acesso em: 27 de jun. de 2021.

COVID-19: Cartilha faz recomendações sobre grupos de risco e suspeitas, 2020. Disponível em:

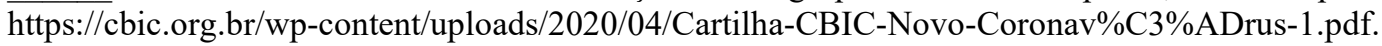
Acesso em: 17 de jun. de 2021.

DEKKER, S.; WOODS, D. The High Reliability Organization Perspective. In: SALAS, E; MAURINO, D (Ed.) Human Factors in Aviation. London: Elvesier. Cap. 5, p. 123-143, 2010.

HALPIN, D. W; WOODHEAD, R. W. Administração da construção civil. Rio de Janeiro: LTC, 2015.

JOSHI, A.; BHASKAR, P.; GUPTA, P. K. Indian Economy Amid COVID-19 Lockdown: A Perspective. J. Pure Appl. Microbiol, 14, 957-961. 2020.

LEE, Y. C.; SHARIATFAR, M.; RASHIDI, A.; LEE, H. W. (2020). Evidence-driven sound detection for prenotification and identification of construction safety hazards and accidents. Automation in Construction, 113, 103127.

OCCUPATIONAL SAFETY AND HEALTH ADMINISTRATION (OSHA). COVID-19 Control and Prevention: Construction Work. 2021.

RIBEIRO, M. Organização da atenção primária à saúde para o enfrentamento da COVID-19: Experiência de Sobral-CE. 2020.

SINDUSCON-SP. Atual cenário econômico provoca grande entusiasmo na construção civil, 2020. Disponível em: https://sindusconsp.com.br/regional/todos/page/58/. Acesso em: 15 de jun. de 2021.

SINDUSCON-SP. Diminui o percentual de casos confirmados de COVID-19 nas obras paulistas, 2021. Disponível em: https://sindusconsp.com.br/diminui-o-percentual-de-casos-confirmados-de-covid19-nas-obras-paulistas/. Acesso em: 10 de jun. de 2021.

YIN, R.K. Estudo de caso: planejamento e métodos. 4ª ed, 2010. Porto Alegre (RS): Bookman. 